\title{
Ectopic pancreas formation in Hes1-knockout mice reveals plasticity of endodermal progenitors of the gut, bile duct, and pancreas
}

Akihisa Fukuda, ${ }^{1,2,3}$ Yoshiya Kawaguchi, ${ }^{1,4}$ Kenichiro Furuyama, ${ }^{1}$ Sota Kodama, ${ }^{1}$ Masashi Horiguchi, ${ }^{1}$ Takeshi Kuhara, ${ }^{1}$ Masayuki Koizumi, ${ }^{1}$ Daniel F. Boyer, ${ }^{5}$ Koji Fujimoto, ${ }^{1}$ Ryuichiro Doi, ${ }^{1}$ Ryoichiro Kageyama, ${ }^{6}$ Christopher V.E. Wright, ${ }^{5}$ and Tsutomu Chiba ${ }^{2}$

\begin{abstract}
1Department of Surgery and Surgical Basic Science and 2Department of Gastroenterology and Hepatology, Kyoto University Graduate School of Medicine,

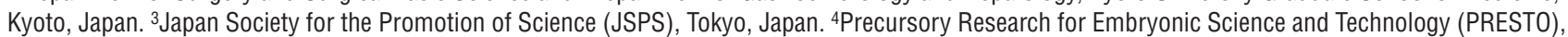
Japan Science and Technology Agency, Kawaguchi, Japan. ${ }^{5}$ Vanderbilt Developmental Biology Program, Department of Cell and Developmental Biology, Vanderbilt University School of Medicine, Nashville, Tennessee, USA. ${ }^{6}$ Institute for Virus Research, Kyoto University, Kyoto, Japan.
\end{abstract}

Ectopic pancreas is a developmental anomaly occasionally found in humans. Hes1, a main effector of Notch signaling, regulates the fate and differentiation of many cell types during development. To gain insights into the role of the Notch pathway in pancreatic fate determination, we combined the use of Hes1-knockout mice and lineage tracing employing the Cre/loxP system to specifically mark pancreatic precursor cells and their progeny in Ptf1a-cre and Rosa26 reporter mice. We show that inactivation of Hes 1 induces misexpression of $P t f 1 a$ in discrete regions of the primitive stomach and duodenum and throughout the common bile duct. All ectopic Ptf1a-expressing cells were reprogrammed, or transcommitted, to multipotent pancreatic progenitor status and subsequently differentiated into mature pancreatic exocrine, endocrine, and duct cells. This process recapitulated normal pancreatogenesis in terms of morphological and genetic features. Furthermore, analysis of $\mathrm{Hes} 1 / \mathrm{Ptfla}$ double mutants revealed that ectopic Ptf1a-cre lineage-labeled cells adopted the fate of regionappropriate gut epithelium or endocrine cells similarly to Ptfla-inactivated cells in the native pancreatic buds. Our data demonstrate that the Hes1-mediated Notch pathway is required for region-appropriate specification of pancreas in the developing foregut endoderm through regulation of Ptfla expression, providing novel insight into the pathogenesis of ectopic pancreas development in a mouse model.

\section{Introduction}

The site of organ/tissue formation is usually determined by strictly coordinated developmental programs involving interplay between extracellular signaling and intracellular transcriptional factor networks. Yet at times, these developmental regulatory mechanisms do not function properly, as tissues are occasionally formed at ectopic locations in humans (1). For example, ectopic thyroid may form an enlarging mass in the neck or tongue; ectopic uterine epithelium in the colon or rectum causes intestinal bleeding according to the menstrual cycle; and $10 \%$ of pheochromocytomas are found in ectopic adrenal tissue. In addition, ectopic pancreas is a developmental anomaly occasionally found in humans, with highest frequencies in the distal stomach, duodenum, and jejunum (2) but also infrequent occurrence in the biliary tree, including the major duodenal papilla (MDP) $(2,3)$. Ectopic pancreas is usually an asymptomatic condition, incidentally found at endoscopy, surgery, or autopsy. Ectopic pancreas sometimes causes symptoms associated with pancreatitis, ulceration, gastrointestinal bleeding, gastric outlet obstruction, biliary obstruction with jaundice, intestinal obstruction, and intussusception (2). In some cases, ectopic pancreas results in malignant degeneration, cyst formation, and

Nonstandard abbreviations used: bHLH, basic helix-loop-helix; CBD, common bile duct; DBA, Dolichos biflorus agglutinin; MDP, major duodenal papilla; Ngn3, neurogenin3; Pdx1, pancreatic and duodenal homeobox gene-1; PP, pancreatic polypeptide; Ptf1a, pancreas-specific transcription factor, 1a; ROSA26r, ROSA26 reporter.

Conflict of interest: The authors have declared that no conflict of interest exists.

Citation for this article: J. Clin. Invest. 116:1484-1493 (2006). doi:10.1172/JCI27704. islet tumors (2). The precise pathogenetic mechanism of ectopic pancreas development remains unclear.

Notch signaling is an evolutionarily conserved mechanism that regulates cell fate determination and differentiation during development of various tissues and organs $(4,5)$. To date, 4 Notch receptors have been identified in mammals, known as Notch1, Notch2, Notch3, and Notch4, and 5 Notch ligands have been identified: Jagged1, Jagged2, Delta-like1, Delta-like3, and Delta-like4. Activation of Notch receptors, by binding with ligands expressed on adjacent cells, leads to proteolytic release and nuclear translocation of the intracellular domain of Notch (NotchIC). NotchIC acts as a transcriptional activator in cooperation with DNA-binding protein RBP-Jk and activates expression of the negative basic helixloop-helix (bHLH) Hes genes, including Hes1 and Hes5, which have critical roles in regulating differentiation of multiple cell types (6). Hes1 generally maintains cells in an undifferentiated precursor state by negatively regulating bHLH transcription factors including neurogenin 3 (Ngn3), MyoD, and Math1 (6-8).

On the other hand, specification of progenitor cells to organ-specific identities is often promoted by region-specific transcriptional regulators. One such factor is pancreatic and duodenal homeobox gene-1 (Pdx1), which is expressed in the epithelia of the pancreas, duodenum, antral stomach, common bile duct (CBD) (9), and MDP (10) and plays a pivotal role in pancreas organogenesis: $P d x 1$-null mutants have an early block in pancreas formation $(9$, 11). Krapp and colleagues reported that pancreas-specific transcription factor, 1a (Ptf1a; PTF1-p48), a bHLH transcription factor, is also indispensable for the formation of the exocrine and the correct 

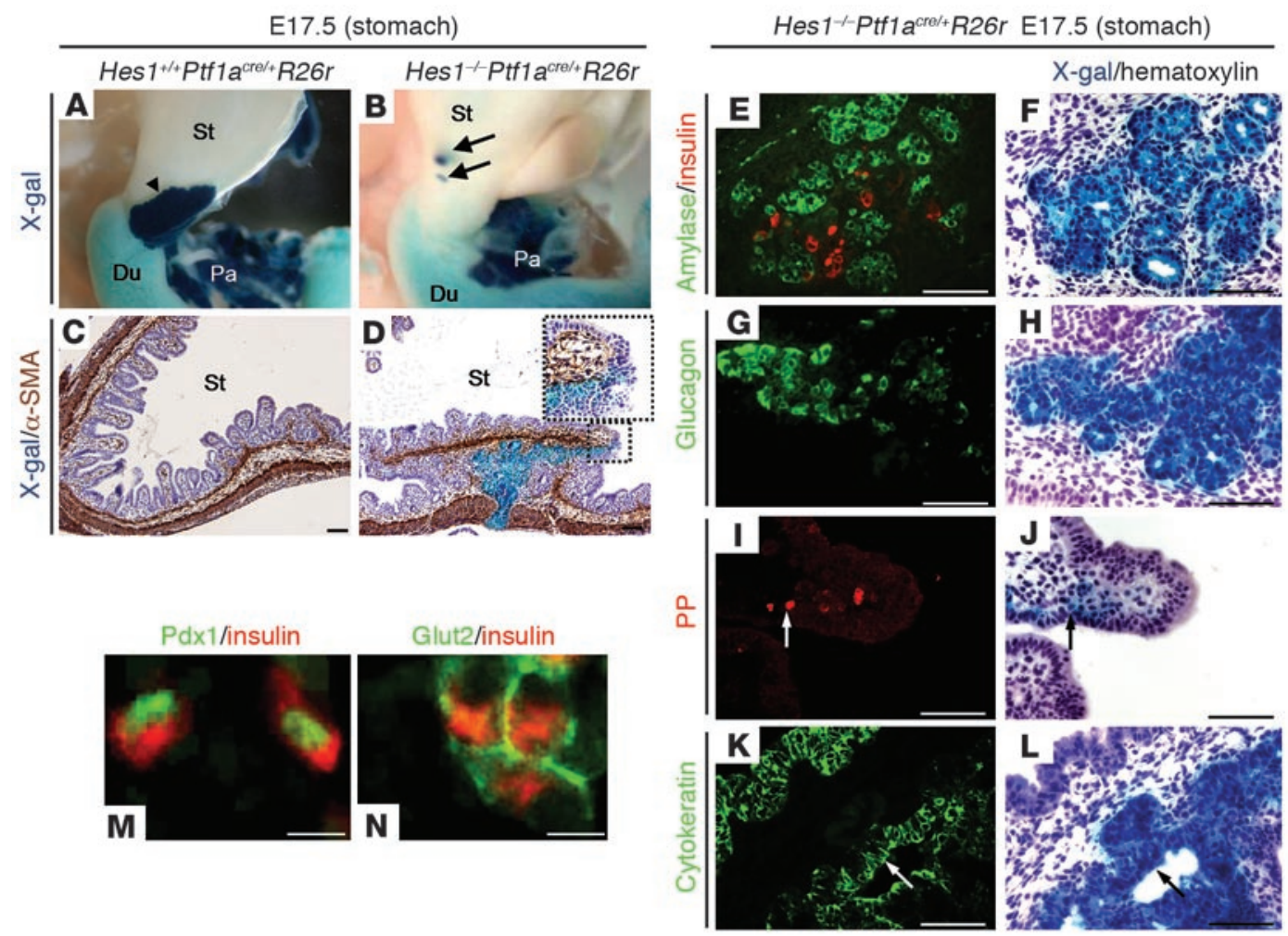

Figure 1

Ectopic formation of Ptf1a lineage-labeled pancreatic tissue at the distal stomach in Hes1-1-Ptf1 $a^{\text {cre/WT}}$ ROSA26r mice. In macroscopic views of the X-gal-stained stomach at E17.5, the ectopic Ptf1a lineage-labeled areas were observed in the distal stomach in Hes $1^{-l-P t f 1 a^{c r e / W T} R O S A 26 r}$

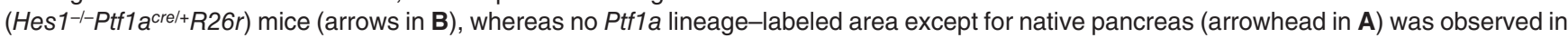

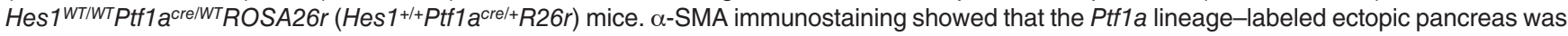
continuous with the stomach epithelium (inset in $\mathbf{D}$ ) and penetrated the submucosal and proper muscular layers of the distal stomach in Hes1-null mice (D). Histological analysis of the ectopic pancreas using the thin sections showed overlap of $\beta$-galactosidase and pancreatic markers including amylase and insulin (E and F), glucagon (G and $\mathbf{H}$ ), PP (arrows in I and $\mathbf{J}$ ), and cytokeratin (arrows in $\mathbf{K}$ and $\mathbf{L}$ ) in Hes1--Ptf1acre/WTROSA26r mice. The ectopic pancreatic exocrine cells had acinar structures with polarized cells surrounding a small lumen (F). The ectopic insulin-positive cells coexpressed nuclear Pdx1 (M) and cell-membranous Glut2 (N). Du, duodenum; St, stomach; Pa, pancreas. Scale bars: 50 um (A-L) and $10 \mu \mathrm{m}$ (M and $\mathbf{N})$.

spatial organization of the endocrine pancreas in mice (12). Using Cre-mediated genetic lineage tracing of cells that activate the Ptfla gene, we have shown previously that all pancreatic exocrine cells and most endocrine cells are the progeny of Ptf1a-expressing precursor cells, and a combination of gene knockout and lineage tracing revealed that $P t f 1 a$-inactivated cells revert to an intestinal cell fate, demonstrating that Ptfla functions as a transcriptional switch between pancreatic and intestinal cell fates (13).

Several lines of evidence indicate that Notch signaling pathway plays important roles in regulating pancreatic cytodifferentiation during development. Inactivation of Delta-like1 or RBP-Jk leads to an increase in endocrine cells (14). In addition, previous analysis of Hes1-null mice showed that accelerated endocrine cytodifferentiation occurs at the expense of proliferation of the undifferentiated precursor pool, resulting in pancreatic hypoplasia (15). Moreover, recent studies have shown that the Notch pathway also regulates pancreatic exocrine cytodifferentiation (16-18). Pancreas-specific Notch1 overexpression results in prevention of exocrine as well as endocrine cytodifferentiation $(16,17)$, and Notch inhibits Ptf1a function and acinar cell differentiation in both mice and zebrafish (18). Furthermore, recent analysis of Hes1-null mice has shown that much of the CBD is replaced by mature pancreatic tissue consisting of both exocrine and endocrine cells (19).

What is the precise mechanistic relationship of the Notch signaling pathway and ectopic pancreas formation? Understanding the mechanism of ectopic tissue formation will be an important advance in our ability to understand the mechanism of the strictly orchestrated developmental program for endogenous organogenesis, specification, and differentiation. Although Sumazaki et al. showed that pancreatic conversion of the CBD in Hes1-null mice is preceded by upregulation of $\mathrm{Ngn3}$, a proendocrine bHLH gene (19), the underlying mechanism remains unclear, considering that Ngn3-expressing cells differentiate into endocrine cells but not pancreatic exocrine or duct cells $(20,21)$.

On this basis, we hypothesized that Ptfla also plays a pivotal role in ectopic pancreas development and that the Notch signaling pathway is involved in the regulation Ptfla expression and pancreatic fate determination. To address these issues, we took advantage of combining Hes 1 knockout and Ptfla-cre-mediated lineage tracing. If Ptfla also functions in the formation of ectopic pancreas, the Ptf1a-cre-based lineage tracing technique (13) should be a powerful tool for investigating systematically and rigorously 


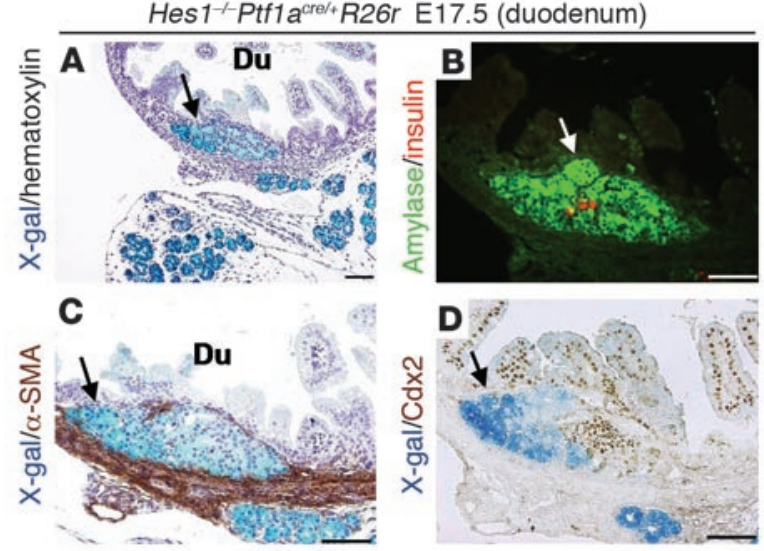

where and how ectopic pancreas is formed when genes involved in body patterning, such as Hes 1 , are manipulated.

Here we show that inactivation of Hes 1 induces misexpression of Ptfla in discrete regions of the primitive stomach and duodenum as well as throughout the CBD. Rigorous lineage tracing revealed that all the ectopic Ptf1a-expressing cells were transcommitted to multipotent pancreatic progenitor status and subsequently differentiated into mature pancreatic cells, including exocrine, endocrine, and duct cells. This process recapitulates normal pancreatogenesis in terms of morphological and genetic features. Furthermore, analysis of Hes1/Ptf1a double mutants revealed that ectopic Ptf1a-cre lineage-labeled cells become region-appropriate gut epithelial or ectopic endocrine cells. Our results provide in vivo evidence of the requirement for Notch pathway in region-appropriate allocation of pancreatic field identity in the developing endoderm through its regulation of Ptf1a expression.

\section{Results}

Lineage tracing of Ptf1a-expressing cells reveals ectopic pancreas formation in the stomach and duodenum and throughout CBD in Hes1null mice. We analyzed Hes1-/-;Ptf1 $a^{\text {tm1(cre)Wri }}$ (Ptf1 $a^{\text {cre/WT }}$ or Ptf1a-

\section{Figure 3}

Ectopic pancreas formation in the CBD and MDP in Hes1-l-Ptf1 acre/WT $^{\text {ch }}$ ROSA26r mice. Macroscopic and microscopic views of the X-galstained CBD at E17.5 show that the Ptf1a lineage-negative normal CBD in Hes $1^{W T / W T}$ mice (arrows in A) was replaced by Ptf1a lineagelabeled pancreatic tissue in Hes1-null mice (arrows in B and D). Note that the duodenum is light blue because of endogenous $\beta$-galactosidase activity. The converted pancreatic tissue extended from the site where the cystic duct would have joined the CBD to the junction with the duodenum (B). Note that the native ventral pancreas (arrow in $\mathbf{C}$ ) and rare cells just beside the CBD (arrowhead in C) were Ptf1a lineage labeled in Hes1 ${ }^{\text {WT/WT }}$ mice. The DBA-positive CBD epithelium at the MDP (E) was replaced by DBA-negative, Ptf1a lineage-labeled pancreatic tissue in Hes1-null mice (F). Neither amylase- nor insulin-producing cells were present in the CBD in Hes1WT/WT mice (G). (H) Double immunostaining showed that the ectopic pancreatic tissue at the MDP was positive for amylase and insulin in Hes1-null mice (note that $\mathbf{F}$ and $\mathbf{H}$ are adjacent sections). The normal structure of the MDP is shown (I). (J) Ectopic pancreatic tissue penetrated the duodenal wall at the MDP, shown by $\alpha$-SMA immunostaining. Cdx2 immunostaining showed that $\mathrm{Cdx} 2$ was not expressed in the biliary epithelium (arrow in K) and the ectopic pancreas (arrow in $\mathbf{L}$ ) but was expressed in the duodenal epithelium ( $\mathbf{K}$ and L). Papilla, MDP; VP, ventral pancreas. Scale bars: $50 \mu \mathrm{m}$.

\section{Figure 2}

Ectopic pancreas formation in the duodenum in $\mathrm{Hes} 1^{-1-P t f 1} \mathrm{a}^{\text {cre/WT }}$ ROSA26r mice. Ectopic pancreas was observed in the duodenum in Hes 1-1-Ptf1 a ${ }^{\text {cre/WT} R O S A 26 r ~ m i c e ~ a t ~ E 17.5 ~(a r r o w s ~ i n ~ A-D) . ~ E c t o p i c ~ P t f 1 a ~}$ lineage-labeled pancreatic cells expressed amylase and insulin in the duodenum ( $\mathbf{A}$ and $\mathbf{B}$ ) and were located in the submucosal layer of the duodenum in Hes1-null mice (C). (D) Cdx2 immunostaining showed that Cdx2 was not expressed in the ectopic pancreatic cells but is expressed in the adjacent duodenal epithelial cells. Scale bars: $50 \mu \mathrm{m}$.

cre);Gt(ROSA)26Sortm1Sor (ROSA26 reporter [ROSA26r]) mice (13, $22,23)$. In these mice, Ptf1a-driven expression of Cre excises a stop cassette upstream of $l a c Z$, which has been inserted into the ubiquitously transcribed ROSA26r gene (23), and activates $\beta$-galactosidase expression in all Ptf1a-expressing cells and their progeny (13). Thus, we can easily detect all the progeny of Ptf1a-expressing cells in the absence of Hes 1 by X-gal staining. We identified candidate sites of ectopic pancreas formation by comparing the

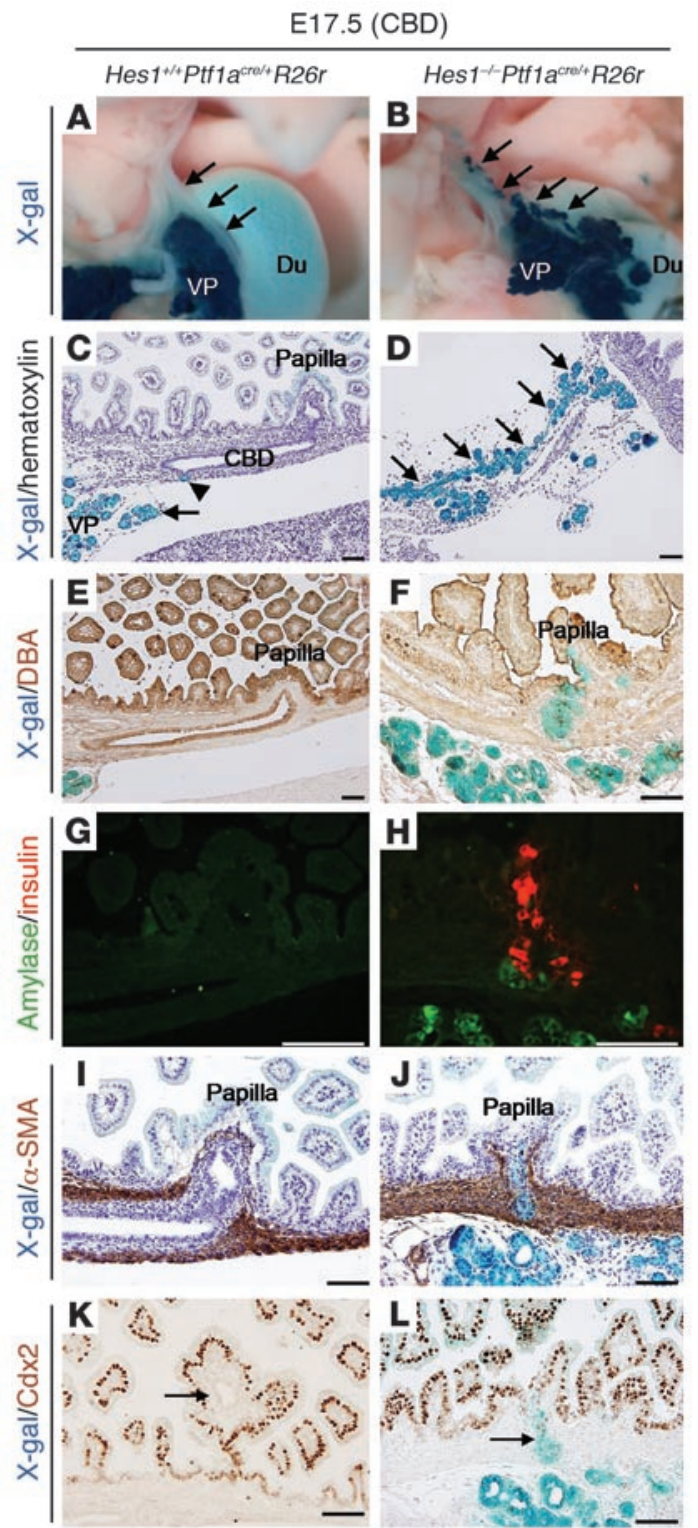


A

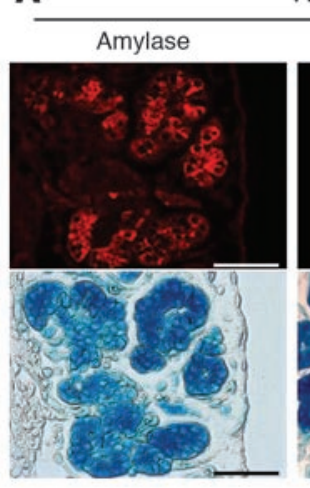

B

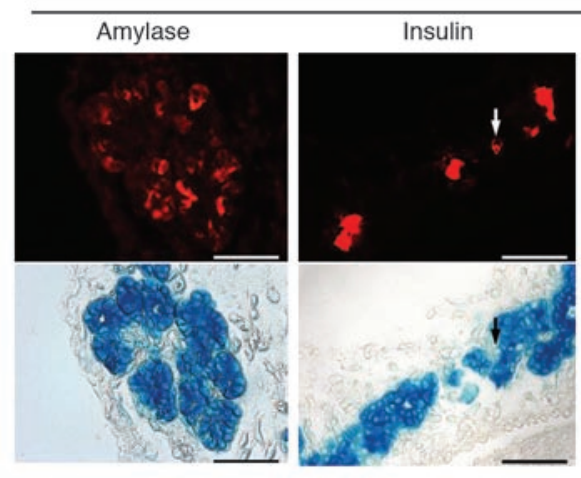

Hes $1^{+/+} P t f 1 a^{c r e /+} R 26 r$ E17.5 (ventral pancreas)
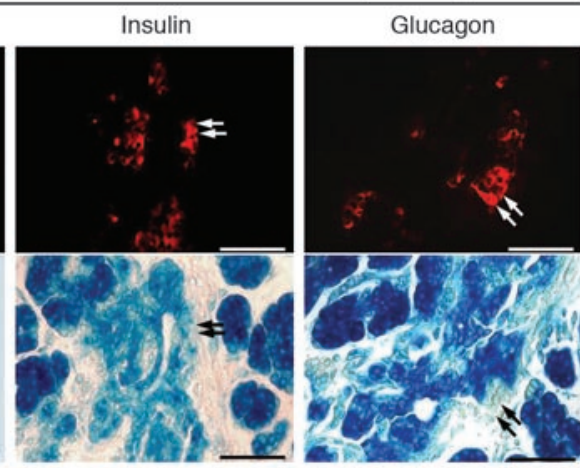

E17.5 (CBD region)

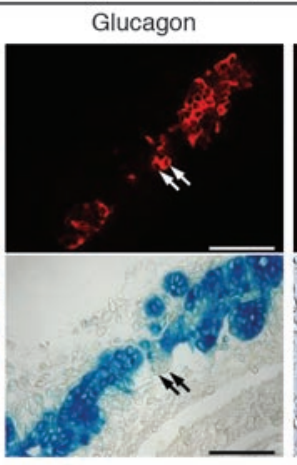

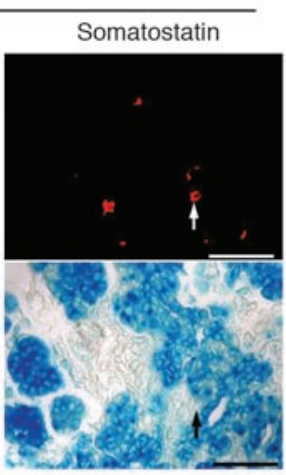

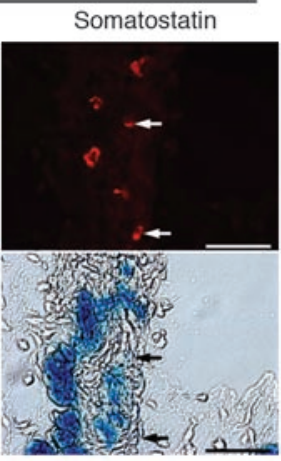

\section{Figure 4}

Estimation of Ptf1a lineage-labeled ratio in ectopic pancreatic cells. Histological analysis using the thin $(3-\mu \mathrm{m})$ sections indicated coexpression of $\beta$-galactosidase and pancreatic markers (amylase, insulin, glucagon, and somatostatin) in the ventral pancreas in Hes ${ }^{\text {WT/WT}}$ Ptf1a ${ }^{\text {cre/WT }}$ ROSA26r mice (A) and in the CBD region (ectopic pancreas) in $\mathrm{Hes}^{-/-}$

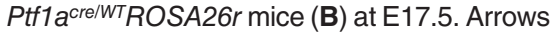
indicate Ptf1a lineage-negative pancreatic endocrine cells. The calculated percentage of Ptf1a lineage labeling in each of the cell types was similar in Hes1WT/WTPtf1acre/WT ROSA26r and Hes1-l-Ptf1 $a^{\text {cre/WT }}$ ROSA26r mice (see Results). Scale bars: $50 \mu \mathrm{m}$. location of $\beta$-galactosidase-expressing tissue in $\mathrm{Hes}^{-/-P t f 1 a^{\text {cre/WT }}}$

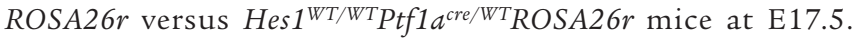
Remarkably, X-gal staining revealed that ectopic Ptf1a lineagelabeled areas were found in the distal stomach along the greater curvature in Hes 1--Ptf1 acre/WTROSA26r mice (Figure 1, B and D), whereas no Ptf1a lineage-labeled area was observed in the stom-

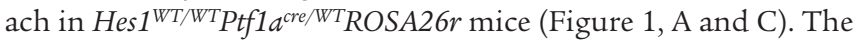
significant amounts of relatively patchy X-gal-positive tissue were reproducibly located in this same place in the distal stomach $(n=8)$. The ectopic Ptfla lineage-labeled cell populations included cells expressing amylase, insulin, glucagon, pancreatic polypeptide

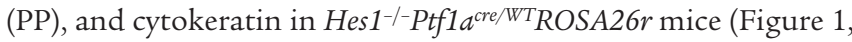
$\mathrm{E}-\mathrm{L}$ ), indicating that all pancreatic cell types could be detected in the ectopic location. The ectopic pancreatic exocrine cells in the stomach have acinar structures with polarized cells surrounding a small lumen (Figure 1F), and the ectopic insulin-positive cells coexpressed nuclear Pdx1 (Figure 1M) and plasma membrane-localized Glut2 (Figure 1N), suggesting their full maturation. Notably, $\alpha$-SMA immunostaining revealed that the ectopic pancreatic cells were continuous with the stomach epithelium and penetrated the submucosal and the proper muscular layers of the stomach (Figure 1D), which is reminiscent of the evagination from the foregut endoderm observed in normal pancreatogenesis. We also found ectopic pancreatic cells in the duodenum in Hes1-null mice (Figure 2 , A-D). Such cells were not of an intestinal phenotype, as revealed by absence of $\mathrm{Cdx} 2$, an intestine-specific caudal-type homeobox gene (24), at E17.5 (Figure 2D).

Consistent with the previous report (19), X-gal staining revealed that the CBD was replaced by Ptfla lineage-positive ectopic pancreatic tissue in Hes1-null mice at E17.5, whereas the normal CBD was Ptfla lineage-negative tissue in Hes $1^{\text {WT/WT }}$ mice (Figure 3, A-D). The
Ptfla-cre lineage-labeled tissue extended to the MDP, which is located at the junction of the duodenum and CBD and functions to regulate the flow of bile and pancreatic juice into the duodenum, preventing reflux of duodenal contents into the CBD (Figure 3, E-L). Staining with Dolichos biflorus agglutinin (DBA), which marks the bile duct, pancreatic duct, and duodenum $(25,26)$, showed that the DBA-positive normal CBD epithelium at the MDP was replaced by Ptfla lineage-labeled cells that expressed amylase or insulin in Hes1null mice (Figure 3, E-H). $\alpha$-SMA immunostaining revealed that the ectopic pancreas penetrated the proper muscular layer of the duodenum in Hes1-null mice (Figure 3, I and J). Furthermore, Cdx2 was not expressed in the ectopic pancreatic cells but was expressed in the adjacent duodenal epithelial cells, with a well-defined boundary (Figure 3, K and L). This finding suggests the important conclusion that the establishment of a boundary between the 2 different epithelia at the MDP is maintained despite the absence of Hes1.

Our previous analysis revealed that all pancreatic exocrine cells and most endocrine cells are Ptfla lineage labeled (13). We examined the frequencies of coexpression of $\beta$-galactosidase and specific pancreatic markers in detail in the ectopic pancreatic cells. Notably, the frequencies of coexpression of $\beta$-galactosidase and specific pancreatic markers were almost the same in the CBD region in Hes1-null mice (amylase, 100\%; insulin, 92\%; gon, 81\%; and somatostatin, 95\%) (Figure 4B) as in the proper ventral pancreas in Hes $1^{W T / W T}$ mice (amylase, 100\%; insulin, 93\%; glucagon, 80\%; and somatostatin 94\%) (Figure 4A), suggesting the genetic recapitulation of normal pancreatogenesis at the ectopic site.

Taken together, our findings indicate that all the ectopic Ptfla lineage-labeled areas were replaced by ectopic pancreatic tissues in the stomach, duodenum, and CBD including the MDP of Hes1-null mice at E17.5. 


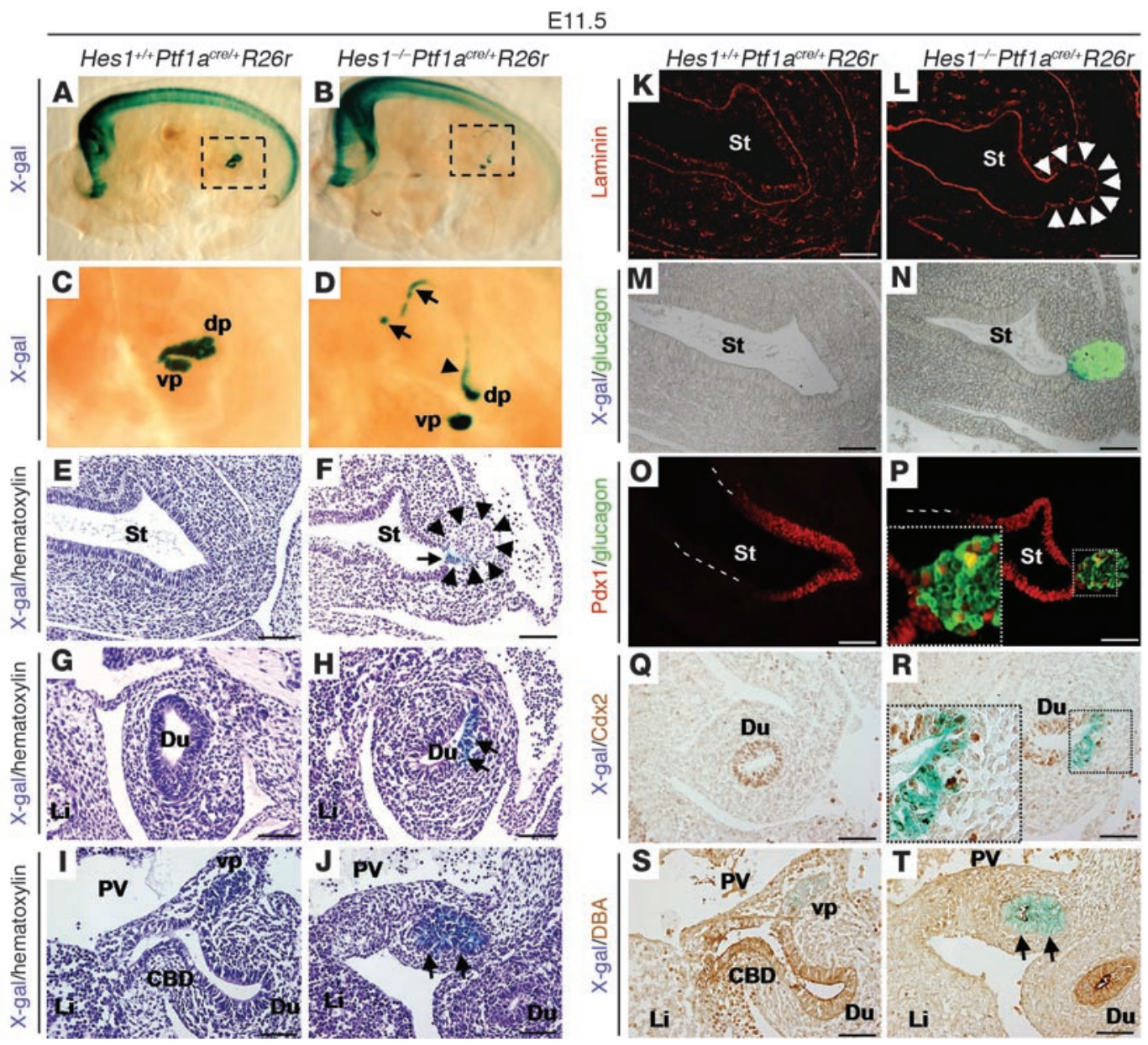

\section{Figure 5}

Transcommitment to pancreatic lineage by misexpression of Ptf1a in the prospective stomach, duodenum, and CBD at E11.5. Macroscopic views of embryos stained with X-gal at E11.5 (A-D; C and D are magnified views of the boxes in $\mathbf{A}$ and $\mathbf{B}$ ). (A and $\mathbf{C})$ Ventral and dorsal pancreatic buds and central nervous system $(42,43)$ were X-gal positive in control mice. Note that misexpression of Ptf1a was observed in

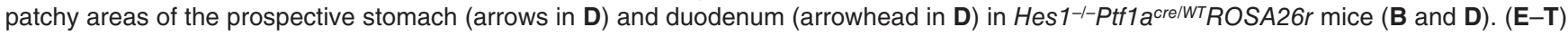
Histological analyses of the same samples shown in A and B. Patchy misexpression of Ptf1a was observed in the prospective stomach (arrow in $\mathbf{F}$ ) and duodenal epithelium (arrows in $\mathbf{H}$ ) in Hes1-I-Ptf1a ${ }^{\text {cre/WT}} R O S A 26 r$ mice. ( $\left.\mathbf{J}\right)$ The CBD did not form at all, but instead is replaced by $\mathrm{X}$-gal-positive aggregated cells in Hes1-l-Ptf1acre/WTROSA26r mice. Laminin immunostaining shows evagination from the stomach epithelium in Hes1-l-Ptf1acre/WTROSA26r mice (arrowheads in F and $\mathbf{L}$ ). (N and $\mathbf{P})$ The evaginated cells consisted of a large number of $\mathbf{X}$-gal-negative, Pdx1negative early glucagon-positive cells. Note that the proximal stomach epithelium was negative for Pdx1 (dotted lines in $\mathbf{O}$ and $\mathbf{P}$ ). $\mathbf{X}$-gal was ectopically observed in the Cdx2-positive duodenal epithelial cells (inset in R). ( $\mathbf{S}$ and T) The DBA-positive CBD was replaced by DBA-negative, X-gal-positive tissue. Li, liver; PV, portal vein; dp, dorsal pancreatic bud; vp, ventral pancreatic bud. Scale bars: $50 \mu \mathrm{m}$. Original magnification, $\times 20(\mathbf{A}$ and $\mathbf{B}), \times 80(\mathbf{C}$ and $\mathbf{D})$.

Ectopic pancreas is induced via transcommitment to multipotent pancreatic progenitors by misexpression of Ptf1a. Next, to gain insight into the origin of the ectopic pancreatic cells, we analyzed the early devel-

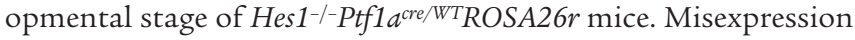
of Ptfla was observed in the prospective stomach and duodenum of Hes1-null mice as early as E11.5, that is, the stage before the pancreatic rudiments rotate around the gut (Figure 5, B, D, F, and $\mathrm{H})(n=6)$. Immunostaining for laminin, a basement membrane protein, showed evagination from the stomach epithelium in Hes1null mice (Figure 5L), and the evaginated cells were predominantly Ptf1a lineage negative, Pdx1-negative early glucagon-positive cells at E11.5 (Figure 5, N and P, and Supplemental Figure 1; supplemental material available online with this article; doi:10.1172/ JCI27704DS1), which disappear before E17.5 (data not shown).
These glucagon-positive cell clusters were reminiscent of the Pdx1negative, early glucagon-positive cells observed in the endogenous pancreatic buds of Hes1-null mice (15), suggesting that development of the ectopic pancreas follows the same program as that of the native pancreatic buds. We could not detect pancreatic endocrine cells that coexpress insulin and glucagon at both E11.5 and E17.5 in Hes1-null embryos (data not shown). In the primitive duodenum near the dorsal pancreatic bud, ectopic Ptfla lineage labeling was reproducibly observed in the $\mathrm{Cdx} 2$-positive epithelial cells at E11.5 (Figure 5R). However, Cdx2 expression in these Ptf1a lineage-labeled cells disappeared before E17.5 (Figure 2D), which is the stage in which cytodifferentiation and architectural formation of the gut epithelial cells occurs (24). Considering that $\mathrm{Cdx} 2$ is first expressed at E9.5 in the primitive intestinal epithelium (24), 

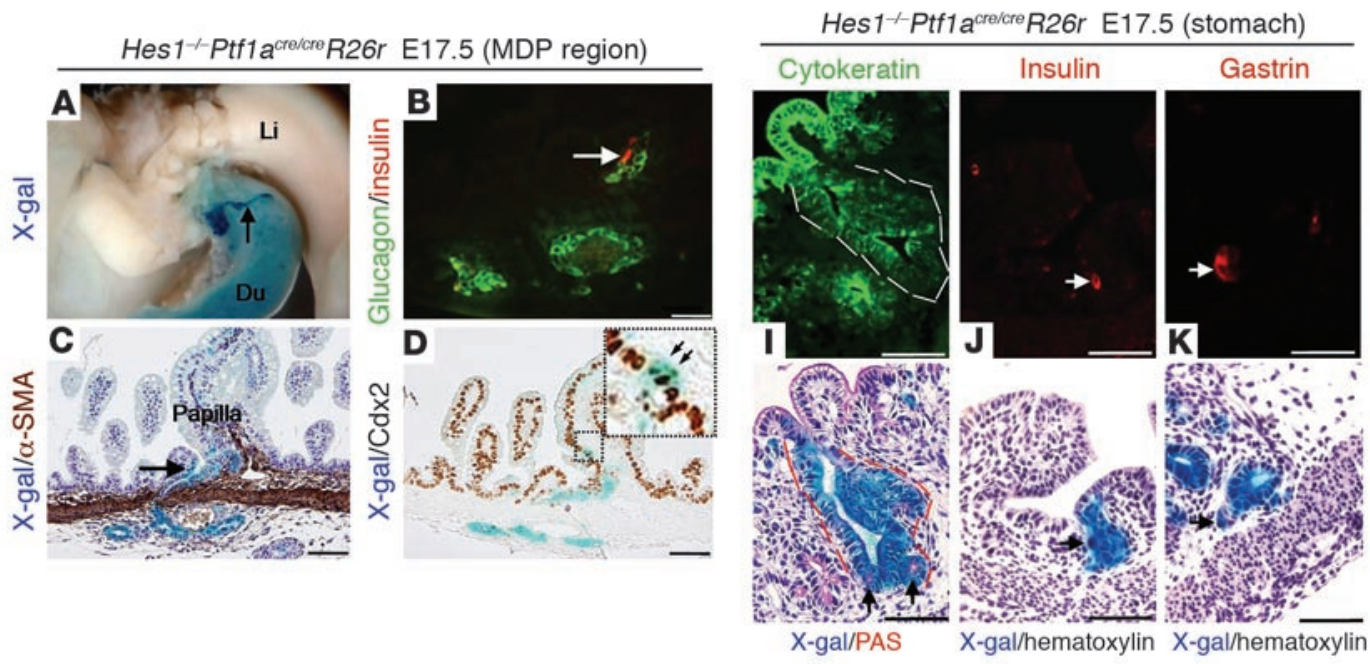

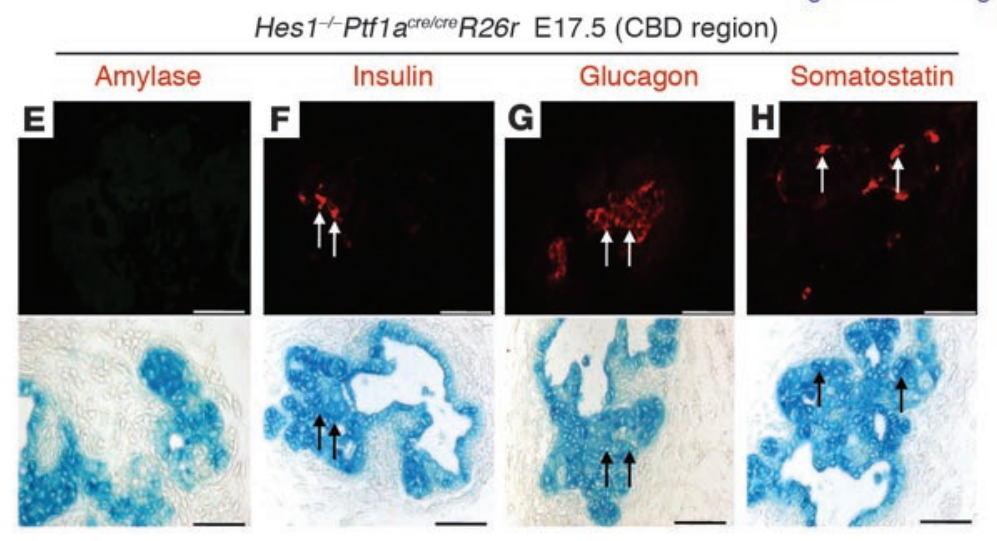

\section{Figure 6}

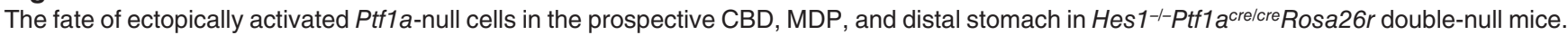
$(\mathbf{A}-\mathbf{H})$ The CBD and MDP region in Hes1 1-Ptf1a ${ }^{\text {cre/cre }}$ Rosa26r double-null mice at E17.5. Macroscopic view of the CBD region stained with $\mathrm{X}$-gal (arrow in A). Double immunostaining showed that X-gal-positive cells at the MDP region were positive for insulin and glucagon (arrows in $\mathbf{B}$ and $\mathbf{C}$ ). (C) $\alpha$-SMA immunostaining showed ectopic pancreatic endocrine cells penetrating the duodenal wall at the MDP region. Cdx2 immunostaining showed that Cdx2/X-gal double-positive cells (arrows in inset, D) were present in the duodenal epithelium. (E-H) Histological analysis of the CBD region in Hes1--Ptf1acre/cre Rosa26r double-null mice on the thin sections. Arrows indicate coexpression of $\beta$-galactosidase and pancreatic markers. (I-K) The distal stomach in Hes 1-l-Ptf1 $a^{\text {cre/cre }}$ Rosa26r double-null mice at E17.5. Many of the X-gal-positive cells in the stomach were PAS positive (arrows in I) and weakly cytokeratin positive (dashed lines in I), indicating differentiation into stomach epithelial cells.

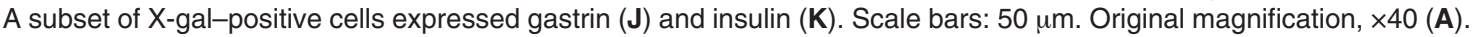

these findings indicate that respecification occurs after initial lineage specification in the absence of Hes1. Furthermore, misexpression of Ptf1a throughout the prospective CBD was observed as early as E11.5, and we could not detect proper CBD formation at that stage (Figure 5, J and T). Taken together, these results suggest that the ectopic pancreatic tissues were generated via reprogramming/transcommitment of the stomach, duodenum, and bile duct progenitors toward multipotent pancreatic progenitor status by misexpression of Ptfla in Hes1-null mice.

Interconversions between distinct precursor cells in the developing endoderm. In order to determine the necessity of Ptf1a in the ectopic induction of multipotent pancreatic progenitors, we traced the fate of the ectopic pancreatic cells after Ptfla inactivation, using Hes $1^{-1}$ $P t f 1 a^{\text {cre/cre }}$ Rosa26r double-null mice. In these mice, $\beta$-galactosidase marks the progeny of cells in which the Ptfla promoter is activated but Ptf1a protein is never expressed. CBD epithelial cells including the MDP were converted to X-gal-positive pancreatic endocrine cells at E17.5 (Figure 6, A-H), but no exocrine cells were detected. $\mathrm{Cd} 22$ immunostaining showed $\mathrm{Cdx} 2 / \mathrm{X}$-gal double-positive cells (Figure 6D), indicating that some of the ectopically activated Ptf1anull cells in the MDP adopted a duodenal cell fate. It should be noted that Ngn3 was ectopically expressed in the CBD epithelium

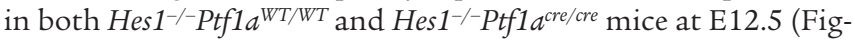
ure $7, \mathrm{~A}-\mathrm{H})$. These results suggest that Hes 1 normally represses $\mathrm{Ngn} 3$ and Ptf1a in parallel in the developing CBD epithelium. In the distal stomach, the majority of the lineage-labeled cells adopted a stomach glandular epithelial cell fate, and the minority of the cells became endocrine cells in the double-null mice and did not evaginate into the proper muscular layer (Figure 6, I-K). The number of ectopic endocrine cells in the stomach of Hes1/Ptf1a double-null mice was remarkably lower than that in Hes1 $1^{-/}$Ptfl $1 a^{\text {cre }} /$ WT ROSA26r mice (data not shown). Thus, inactivation of Ptf1a switches the character of ectopic pancreatic progenitors such that their progeny adopt a gut or pancreatic endocrine cell fate. This is 


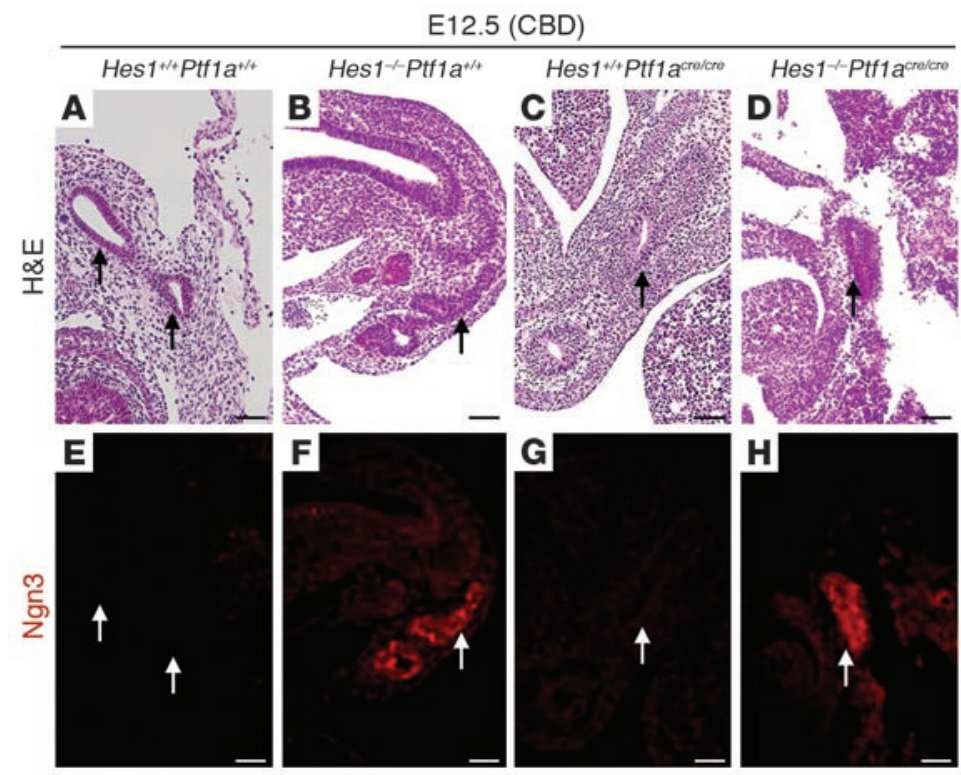

\section{Figure 7}

Hes1 represses Ngn3 and Ptf1a in parallel in the developing $\mathrm{CBD}$ epithelium. Ngn3 was not expressed in the developing CBD epithelium at E12.5 in WT mice (A and E) and Ptf1acre/cre mice (C and $\mathbf{G})$. Ectopic Ngn3 expression was observed in the ectopic pancreatic rudiment in the CBD region at E12.5 in both Hes1-null mice (B and $\mathbf{F}$ ) and Hes1/Ptf1a double-null mice (D and $\mathbf{H})$. Arrows indicate the developing $\operatorname{CBD}(\mathbf{A}, \mathbf{C}, \mathbf{E}$, and $\mathbf{G})$ and the ectopic pancreatic rudiment in the CBD region $(\mathbf{B}, \mathbf{D}$, $\mathbf{F}$, and $\mathbf{H}$ ). Scale bars: $50 \mu \mathrm{m}$.

\section{Discussion}

Notch pathway controls regional specification of pancreas in the developing endoderm by regulating Ptfla expression in mice. We have identified a previously unknown regulatory mechanism by which the Hes1-mediated Notch pathway prevents the stomach and duodenal as well as bile duct progenitors from misexpressing Ptfla and thereby transcommitting to a pancreatic fate during development. Thus, the Notch pathway not only regulates cytodifferentiation of lineage-committed pancreatic precursors (14-18) but also is required for region-appropriate pancreatic fate determiconsistent with our previous report that Ptf1a-inactivated cells in the pancreatic buds adopt a gut or pancreatic endocrine cell fate (13). These data indicate that the developing endoderm (primitive stomach, duodenum, and bile duct progenitors) has a sufficient plasticity, including interconversions between distinct precursor cells, and that even further respecification occurs in the absence of Hes 1 and Ptf1a. Taken together, the results indicate that Ptfla is necessary and sufficient for ectopic induction of multipotent pancreatic progenitors but that ectopic induction of endocrine cells does not require Ptfla in Hes1-null mice.

Consistent with this conclusion, our analysis of Hes $1^{-/}-\mathrm{Ptfl} \mathrm{a}^{\text {cre/WT }}$ ROSA26r mutants identified ectopic insulin- and PP-expressing cells that were negative for Ptfla lineage scattered in a distribution similar to enteroendocrine cells in the deep epithelial layer throughout the distal stomach (Figure 8, A-F). A previous Hes1-knockout study (15) revealed that increased endocrine differentiation including CCK/gastrin, glucagon/GLP1, serotonin, GIP, and somatostatin in the distal stomach and duodenum was accompanied by elevated expression of the proendocrine bHLH gene Ngn3 and NeuroD as well as other transcription factors such as Nkx2-2, Isl1, Pax4, and Pax6. Our findings together with the previous data indicate that ectopic pancreatic endocrine cells are formed through the activation of $\mathrm{Ngn} 3$ without Ptf1a function in Hes1-null mice.

With respect to the general pancreatic phenotype, visual inspection of microdissected Hes1-null embryos at E17.5 revealed completely penetrant hypoplastic pancreata (data not shown), as reported in the previous Hes1-knockout study (15). nation in the developing endoderm by regulating Ptf1a expression. Our data also demonstrate that developing endodermal cells have a sufficient plasticity to switch fates to produce the mature tissue characteristic of a different lineage.

We have found that Hes $1^{-/-P t f 1} a^{\text {cre/WT }}$ ROSA26r mice represent a genetically defined mouse model of ectopic pancreas development, and this study provides insight into the pathogenesis of this developmental anomaly. Notably, the locations of the ectopic pancreatic tissues formed in Hes1-null mice (the stomach, duodenum, and CBD including the MDP) are exactly the same as those in humans. Especially in the stomach, ectopic pancreas was found in the distal stomach along the greater curvature in Hes1-null mice, which

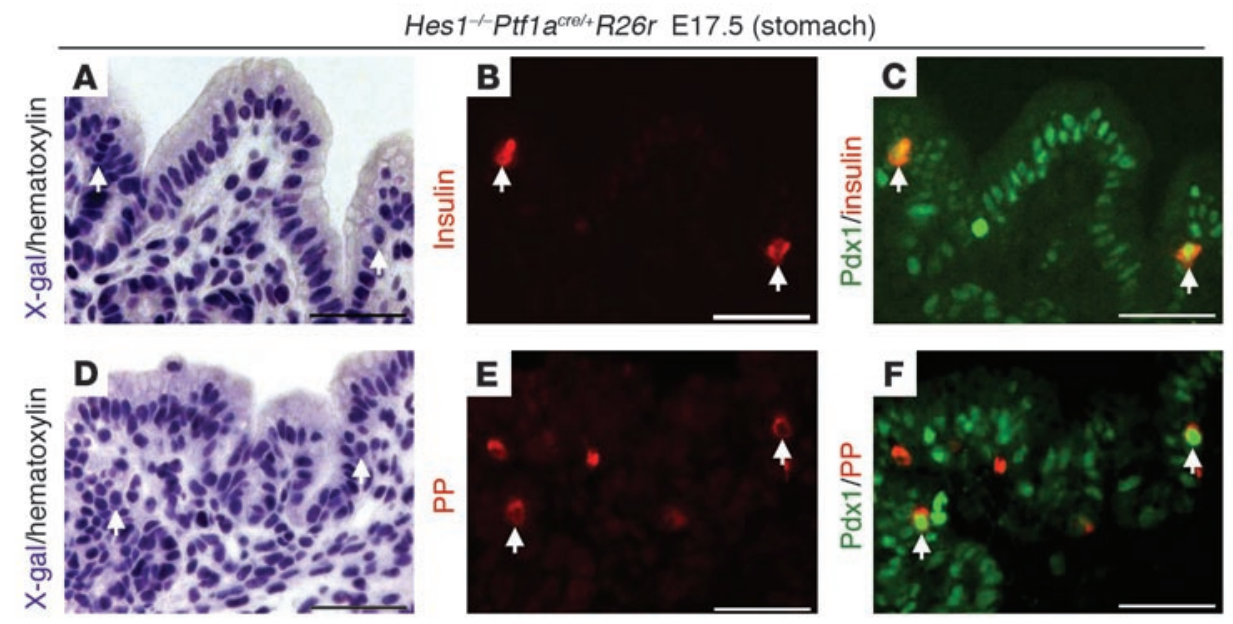

\section{Figure 8}

Ptf1a lineage-negative pancreatic endocrine cells are scattered throughout the distal stomach in Hes1-null mice. X-gal and hematoxylin staining (A and D), immunostaining for insulin and PP (B and E), and double immunostaining for Pdx1/insulin and Pdx1/PP (C and F) in Hes1-l-Ptf1 $a^{\text {cre/WT }}$ ROSA26r mice at E17.5. A-C and D-F show the same sections, respectively. Ptf1a lineage-negative and insulin- and PP- expressing cells were scattered in a distribution similar to that of enteroendocrine cells in the deep epithelial layer throughout the distal stomach in Hes1-null mice, and they were positive for Pdx1 expression. Scale bars: $100 \mu \mathrm{m}$. 
represents the most frequent location of human ectopic pancreas. These results suggest that localized Notch pathway defects may underlie some forms of this disorder. Using Cre-mediated genetic lineage tracing, we clearly show that specified intestinal progenitors are transcommitted toward pancreatic progenitor status by misexpressing Ptfla at the early developmental stage, which is followed by loss of intestinal marker expression and induction of ectopic pancreas in Hes1-null mice, suggesting that this conversion is not due to transdifferentiation of matured cell types. Moreover, we found that, as early as E11.5 - that is, the stage before the pancreatic rudiments rotate around the gut - misexpression of Ptfla is observed in the prospective stomach and CBD as well as duodenal epithelium. This observation strongly supports the notion that the mechanism of ectopic pancreas development in Hes1-null mice is transcommitment of the stomach, bile duct, and duodenal progenitors to pancreatic lineage rather than separation and/or migration from the original pancreatic rudiments into the different sites while rotating around the gut. On the other hand, we did not observe ectopic pancreas formation in the jejunum or mediastinum in Hes1-null mice, which also represent the locations of ectopic pancreas in humans (2). Thus, other embryological "mistakes" may also cause this developmental anomaly.

Although Hes 1 is expressed in a broad region including the entire gut and intrahepatic bile ducts $(15,27)$, it is interesting that the absence of Hes 1 resulted in ectopic pancreas formation at restricted areas in the Hes1-expressing domains. It should be noted that each ectopic pancreas location was within the expression domain of $P d x 1(9,11)$, which is required for the formation of other tissues besides the pancreas but whose expression may demarcate a competence zone for pancreas formation (28). In addition, ectopic pancreas formation was coincident with the expression domain of $\operatorname{Hnf1} \beta(29,30)$, an upstream positive regulator required for Ptf1a and Ngn3 expression (29). Particularly, the focal induction of ectopic pancreas in the distal stomach and duodenum suggests that concerted actions of signals are involved in restricting commitment to a pancreatic fate. One possibility is that a spatially restricted activator triggers Ptf1a expression, and another is that additional negative regulators cooperate with Hes 1 to restrict Ptf1a expression. Consistent with the former possibility, recent studies reported that signals from blood vessels induce Ptf1a expression in the dorsal pancreas (31-33). Some inductive signals from blood vessels, notochord, or mesenchyme are proposed to stimulate endogenous pancreatogenesis, and some of these signals may normally reach the stomach, duodenum, and bile duct progenitors. The normal function of Hes1, therefore, is to prevent the stomach, duodenum, and bile duct progenitors from responding to these signals, possibly by directly repressing Ptfla expression, but in the absence of Hes1, the progenitors that are the closest to the source of the signals may then misexpress Ptf1a. In support of this notion, we identified 2 consensus Hes1-binding sites (CACGCG and CGCGTG) in the Ptfla promoter near the TATAA box at $-47 \mathrm{bp}$ and $-15 \mathrm{bp}$ from the transcriptional initiation site, respectively. The 2 Hes1-binding sites are conserved among mouse, rat, zebrafish, and human, suggesting that Hes 1 is a direct transcriptional regulator of Ptfla.

Other factors that might cooperate with Hes 1 to restrict Ptf1a expression include Hes 3 and Hes $5 / 7$, which are expressed in the developing stomach and small intestine, respectively $(15,34)$. We speculate that compound inactivation of Hes family members may expand the domain of Ptfla misexpression. In addition, a previous study showed that exposure to cyclopamine, a Hedgehog signaling inhibitor, induces ectopic pancreatic tissue in the distal stomach and duodenum, but without the precise regional restriction that we observe in the Hes 1 knockout (35). It would be an interesting experiment to test whether double inactivation of Hedgehog and Notch signaling induces broader misexpression of Ptfla and ectopic pancreas formation in gut endoderm. If this were the case, it would show that Hedgehog and Notch signaling synergistically regulate Ptfla expression and thereby inhibit ectopic pancreas development.

It seems likely that the tissue-specific actions of Notch pathway depend on coupling to unique local combinations of downstream effectors, with Hes 1 being 1 of the factors involved in limiting foregut acquisition of a pancreatic fate. It is possible that other knockouts of extracellular signalings, including Hedgehog signaling, Wnt signaling, and bone morphogenic protein/TGF- $\beta$ signaling, using tracing strategies similar to that described here, will be found to result in different ectopic organ/tissue development.

Ptfla is necessary and sufficient for ectopic induction of the full-scale pancreatic developmental program. Several groups have attempted to induce ectopic pancreatic tissues by misexpressing $\mathrm{Pdx} 1$ in various regions, including the gastrointestinal tract and liver, and some of them succeeded in inducing ectopic expression of pancreatic exocrine and endocrine markers (28, 36-40). In addition, Pdx1-VEGF transgenic embryos had ectopic insulin-expressing cells in the posterior stomach epithelium (31). However, to our knowledge, this is the first experimental genetic model in vivo to generate ectopic pancreatic tissue consisting of exocrine, endocrine, and duct cell compartments. Taking advantage of Cre-mediated genetic lineage tracing system, we provide direct evidence that all the ectopic Ptfla lineage-labeled areas in the stomach, duodenum, and CBD were replaced by ectopic pancreatic tissues, including all the compartments in Hes1-null mice. The ectopic pancreas development through misexpression of $P t f 1$ r recapitulated endogenous pancreatogenesis in morphological and genetic aspects. Furthermore, we have shown that inactivation of Ptfla switches the character of ectopic pancreatic progenitors such that their progeny adopt a gut or pancreatic endocrine cell fate. Therefore, these results provide new evidence that Ptf1a is necessary and sufficient for ectopic induction of multipotent pancreatic progenitors and the subsequent fullscale pancreatic developmental program in the Pdx1-expressing undifferentiated endoderm. Our findings have important implications for possible replacement therapies for diabetes mellitus based on the commitment of naive progenitors, transdifferentiation of differentiated adult cells, and, particularly, reprogramming of abundant developing gut endoderm by forced misexpression of Ptf1a. On the other hand, our analysis of Hes1/Ptf1a double mutants revealed that ectopic pancreatic endocrine cells are formed through the activation of $\mathrm{Ngn} 3$ without Ptf1a function. These findings clearly separate the requirement for a pancreatic fate determination and the induction of the pancreatic endocrine fate and may be relevant to phylogenetic comparisons, considering that the first endocrine pancreas in vertebrate evolution appeared in Agnatha such as sea lamprey, which does not possess exocrine pancreas (41).

The present results suggest a model in which gene regulatory networks induce and maintain the regional specificity of multipotent progenitors in the developing endoderm. More broadly expressed regional transcription factors such as $P d x 1$ and $H n f 1 \beta$ establish competence for cell fates characteristic of the tissues developing in that region, while tissue-specific transcription factors such as 
Ptfla and Cdx2 promote the establishment of committed progenitors for the nascent organs. The overall fidelity of these gene networks is established and reinforced by extracellular signals such as Notch and Hedgehog and their downstream effectors. When some of the effectors of these stabilizing signals are lost (e.g., in the Hes1 mutant), interconversions between regional progenitor identities become possible. The analytical methods presented here and variations thereof could be applied to investigate other incidences of ectopic organ/tissue development.

\section{Methods}

Animals and genotyping. Ptf1 $1 a^{\text {cre/WT }}$ mice (13), Hes 1 heterozygous mice (22), and ROSA26r mice (23) were crossed into the ICR (Japan SLC Inc.) background

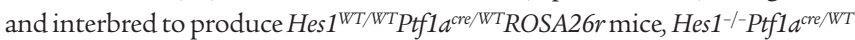

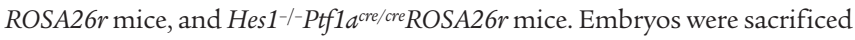
at E11.5, E12.5, and E17.5. Genomic DNA was isolated as described previously (13). Genotyping was performed by PCR. The sequences of the primer sets were as follows: Hes $1^{W T}$ allele, 5'-ATATATAGAGGCCGCCAGGGCCTGCGGATC- $3^{\prime}$ and $5^{\prime}$-CGCAGGTACTGTCTTACCTTTCTGTGCTCAGAGGCC-3' ${ }^{\prime}$ Hes $1^{-}$allele, $5^{\prime}$-ATATATAGAGGCCGCCAGGGCCTGCGGATC-3' and $5^{\prime}$-CGCTTCCATTGCTCAGCGGTGCTGTCCATC-3'; Ptf1 $a^{\text {cre }}$ allele, 5'-ACCTGAAGATGTTCGCGATTATCT-3' and 5'-ACCGTCAGTACGTGAGATATCTT-3'; $P t f 1 a^{W T}$ allele, $5^{\prime}$-AACCAGGCCCAGAAGGTTAT-3' and 5'-TCAAAGGGTGGTTCGTTCTC-3'; and Rosa26r allele, 5'-ATCCTCTGCATGGTCAGGTC- 3 ' and 5'-CGTGGCCTGATTCATTCC- 3 '. All animal experiments were approved by the Animal Research Committee at the Graduate School of Medicine, Kyoto University, and performed in accordance with its guidelines.

$X$-gal staining. Embryos were fixed (ice-cold $4 \%$ paraformaldehyde/PBS, $4^{\circ} \mathrm{C}$ for 60 minutes), then washed twice (30 minutes each wash) in permeabilization solution ( $2 \mathrm{mM} \mathrm{MgCl}_{2}, 0.01 \%$ sodium deoxycholate, $0.02 \%$ Nonidet P-40 in PBS). Activity of $\beta$-galactosidase was detected using $\mathrm{X}$-gal staining as described previously (13). Stereoscopic pictures were taken using an Olympus Bx51 microscope and a Spot digital camera (Nikon).

Tissue preparation. Samples were postfixed and dehydrated in an increasing ethanol series $(70 \%, 80 \%, 90 \%, 95 \%$, and twice with $100 \%$ ethanol); washed twice with HistoClear (National Diagnostics); infiltrated in HistoClear/paraffin $(1: 1 \mathrm{vol} / \mathrm{vol})$ with 2 changes of paraffin under vacuum at $56^{\circ} \mathrm{C}$; embedded; and cut into $3-\mu \mathrm{m}$ sections.

Histological analysis. We performed staining with DBA using DBA-HRP (EY Laboratories Inc.) as described previously (25), and PAS staining was performed according to the standard protocol.

Immunobistochemistry. After rehydration, the sections were placed in $0.01 \mathrm{~mol} / \mathrm{l}$ sodium citrate buffer ( $\mathrm{pH}$ 6.0) for 40 minutes at $95^{\circ} \mathrm{C}$ and then incubated for 20 minutes at room temperature in $0.3 \%$ hydrogen peroxidase in methanol to block endogenous peroxidase activity. Slides were washed and incubated for 30 minutes at room temperature with Protein Block (Dako), followed by overnight incubation at $4{ }^{\circ} \mathrm{C}$ with mouse antibody against $\alpha$-SMA (Dako) and mouse antibody against $\mathrm{Cdx} 2$ (BioGenex Inc.). The sections were washed in PBS and incubated for 60 minutes with HRP-conjugated anti-mouse IgG (EnVision Kit; Dako) as a secondary antibody and visualized using 3,3'-diaminobenzine tetrahydrochloride color substrate (DAB; Dako). Finally, the sections were counterstained with Mayers hematoxylin.

Immunofluorescence. For immunostaining, we used guinea pig antibody against insulin (Dako), rabbit antibody against amylase (Sigma-Aldrich), rabbit antibody against glucagon (Dako), rabbit antibody against somatostatin (Dako), rabbit antibody against PP (Dako), rabbit antibody against gastrin (Dako), goat antibody against pdx1, goat antibody against Glut2 (Santa Cruz Biotechnology Inc.), rabbit antibody against Ngn3 (a gift from M. German, University of California, San Francisco, San Francisco, California, USA), mouse antibody against cytokeratin (Dako), and rabbit antibody against laminin (Sigma-Aldrich). The immunofluorescent secondary antibodies used were $\mathrm{Cy} 3$-conjugated antibody against guinea pig IgG (Chemicon International), Cy3-conjugated antibody against rabbit IgG (Chemicon International), Alexa Fluor 488-conjugated antibody against rabbit IgG (Invitrogen Corp.), Alexa Fluor 488-conjugated antibody against mouse IgG (Invitrogen Corp.), and Alexa Fluor 488-conjugated antibody against goat IgG (Invitrogen Corp.). Images were visualized using Zeiss Axioskop 2 microscope.

\section{Acknowledgments}

We thank Maureen Gannon for critical reading of the manuscript. We thank Hiroshi Seno and Yoshio Fujitani for helpful discussion and Tadao Serikawa and the staff of the Institute of Laboratory Animals of Kyoto University for animal care. This work was supported by PRESTO of Japan, Research Fellowships of the JSPS for Young Scientists, and Grants-in-Aid for Scientific Research (18209027) from the JSPS.

Received for publication December 19, 2005, and accepted in revised form March 22, 2006.

Address correspondence to: Yoshiya Kawaguchi, Department of Surgery and Surgical Basic Science, Kyoto University Graduate School of Medicine, Kawahara-cho 54, Shogoin, Sakyo-ku, Kyoto 606-8507, Japan. Phone: 81-75-751-3444; Fax: 81-75-751-4390; E-mail: yoshiyak@kuhp.kyoto-u.ac.jp.
1. Rosai, J., and Ackerman, L.V. 2004. Rosai and Ackerman's surgical pathology. 9th edition. Mosby. Edinburgh, United Kingdom/New York, New York, USA. 3080 pp.

2. Yamada, T. 1995. Textbook of gastroenterology. Volume 2. Lippincott. Philadelphia, Pennsylvania, USA. 151 pp.

3. Chen, C.H., Yang, C.C., Yeh, Y.H., Chou, D.A., and Kuo, C.L. 2001. Ectopic pancreas located in the major duodenal papilla: case report and review. Gastrointest. Endosc. 53:121-123.

4. Jarriault, S., et al. 1995. Signalling downstream of activated mammalian Notch. Nature. 377:355-358.

5. Artavanis-Tsakonas, S., Rand, M.D., and Lake, R.J. 1999. Notch signaling: cell fate control and signal integration in development. Science. 284:770-776.

6. Kageyama, R., Ohtsuka, T., and Tomita, K. 2000. The bHLH gene Hes1 regulates differentiation of multiple cell types. Mol. Cells. 10:1-7.

7. Lee, J.C., et al. 2001. Regulation of the pancreatic pro- endocrine gene neurogenin3. Diabetes. 50:928-936.

8. Kuroda, K., et al. 1999. Delta-induced Notch signaling mediated by RBP-J inhibits MyoD expression and myogenesis. J. Biol. Chem. 274:7238-7244.

9. Offield, M.F., et al. 1996. PDX-1 is required for pancreatic outgrowth and differentiation of the rostral duodenum. Development. 122:983-995.

10. Fukuda, A., et al. 2006. Loss of the major duodenal papilla results in brown pigment biliary stone formation in $p d x 1$ null mice. Gastroenterology. 130:855-867.

11. Jonsson, J., Carlsson, L., Edlund, T., and Edlund, H. 1994. Insulin-promoter-factor 1 is required for pancreas development in mice. Nature. 371:606-609.

12. Krapp, A., et al. 1998. The bHLH protein PTF1-p48 is essential for the formation of the exocrine and the correct spatial organization of the endocrine pancreas. Genes Dev. 12:3752-3763.

13. Kawaguchi, Y., et al. 2002. The role of the transcriptional regulator $\mathrm{Ptf} 1 \mathrm{a}$ in converting intestinal to pancreatic progenitors. Nat. Genet. 32:128-134.

14. Apelqvist, A., et al. 1999. Notch signalling controls pancreatic cell differentiation. Nature. 400:877-881.

15. Jensen, J., et al. 2000. Control of endodermal endocrine development by Hes-1. Nat. Genet. 24:36-44.

16. Murtaugh, L.C., Stanger, B.Z., Kwan, K.M., and Melton, D.A. 2003. Notch signaling controls multiple steps of pancreatic differentiation. Proc. Natl. Acad. Sci. U. S. A. 100:14920-14925.

17. Hald, J., et al. 2003. Activated Notch1 prevents differentiation of pancreatic acinar cells and attenuate endocrine development. Dev. Biol. 260:426-437.

18. Esni, F., et al. 2004. Notch inhibits Ptf1 function and acinar cell differentiation in developing mouse and zebrafish pancreas. Development. 131:4213-4224.

19. Sumazaki, R., et al. 2004. Conversion of biliary system to pancreatic tissue in Hes1-deficient mice. Nat. Genet. 36:83-87.

20. Gu, G., Dubauskaite, J., and Melton, D.A. 2002. 
Direct evidence for the pancreatic lineage: NGN3+ cells are islet progenitors and are distinct from duct progenitors. Development. 129:2447-2457.

21. Gradwohl, G., Dierich, A., LeMeur, M., and Guillemot, F. 2000. Neurogenin 3 is required for the development of the four endocrine cell lineages of the pancreas. Proc. Natl. Acad. Sci. U. S. A. 97:1607-1611.

22. Ishibashi, M., et al. 1995. Targeted disruption of mammalian hairy and Enhancer of split homolog-1 (HES-1) leads to up-regulation of neural helixloop-helix factors, premature neurogenesis, and severe neural tube defects. Genes Dev. 9:3136-3148.

23. Soriano, P. 1999. Generalized lacZ expression with the ROSA26 Cre reporter strain. Nat. Genet. 21:70-71.

24. Silberg, D.G., Swain, G.P., Suh, E.R., and Traber, P.G. 2000. Cdx1 and cdx2 expression during intestinal development. Gastroenterology. 119:961-971.

25. Shiojiri, N., and Katayama, H. 1988. Development of Dolichos biflorus agglutinin (DBA) binding sites in the bile duct of the embryonic mouse liver. Anat. Embryol. (Berl.). 178:15-20.

26. Kobayashi, H., et al. 2002. Lectin as a marker for staining and purification of embryonic pancreatic epithelium. Biochem. Biophys. Res. Commun. 293:691-697.

27. Kodama, Y., Hijikata, M., Kageyama, R., Shimotohno, K., and Chiba, T. 2004. The role of notch signaling in the development of intrahepatic bile ducts. Gastroenterology. 127:1775-1786.

28. Grapin-Botton, A., Majithia, A.R., and Melton, D.A.
2001. Key events of pancreas formation are triggered in gut endoderm by ectopic expression of pancreatic regulatory genes. Genes Dev. 15:444-454.

29. Haumaitre, C., et al. 2005. Lack of TCF2/vHNF1 in mice leads to pancreas agenesis. Proc. Natl. Acad. Sci. U. S. A. 102:1490-1495.

30. Coffinier, C., Barra, J., Babinet, C., and Yaniv, M. 1999. Expression of the vHNF1/HNF1beta homeoprotein gene during mouse organogenesis. Mech. Dev. 89:211-213.

31. Lammert, E., Cleaver, O., and Melton, D. 2001. Induction of pancreatic differentiation by signals from blood vessels. Science. 294:564-567.

32. Yoshitomi, H., and Zaret, K.S. 2004. Endothelial cell interactions initiate dorsal pancreas development by selectively inducing the transcription factor Ptf1a. Development. 131:807-817.

33. Edsbagge, J., et al. 2005. Vascular function and sphingosine-1-phosphate regulate development of the dorsal pancreatic mesenchyme. Development. 132:1085-1092.

34. Schroder, N., and Gossler, A. 2002. Expression of Notch pathway components in fetal and adult mouse small intestine. Gene Expr. Patterns. 2:247-250.

35. Kim, S.K., and Melton, D.A. 1998. Pancreas development is promoted by cyclopamine, a hedgehog signaling inhibitor. Proc. Natl. Acad. Sci. U. S. A. 95:13036-13041.

36. Heller, R.S., Stoffers, D.A., Hussain, M.A., Miller, C.P., and Habener, J.F. 1998. Misexpression of the pancreatic homeodomain protein IDX-1 by the Hoxa-4 promoter associated with agenesis of the cecum. Gastroenterology. 115:381-387.

37. Horb, M.E., Shen, C.N., Tosh, D., and Slack, J.M. 2003. Experimental conversion of liver to pancreas. Curr. Biol. 13:105-115.

38. Ferber, S., et al. 2000. Pancreatic and duodenal homeobox gene 1 induces expression of insulin genes in liver and ameliorates streptozotocininduced hyperglycemia. Nat. Med. 6:568-572.

39. Ber, I., et al. 2003. Functional, persistent, and extended liver to pancreas transdifferentiation. J. Biol. Chem. 278:31950-31957.

40. Sapir, T., et al. 2005. Cell-replacement therapy for diabetes: generating functional insulin-producing tissue from adult human liver cells. Proc. Natl. Acad. Sci. U. S. A. 102:7964-7969.

41. Elliott, W.M., and Youson, J.H. 1993. Development of the adult endocrine pancreas during metamorphosis in the sea lamprey, Petromyzon marinus L. I. Light microscopy and autoradiography. Anat. Rec. 237:259-270.

42. Hoshino, M., et al. 2005. Ptf1a, a bHLH transcriptional gene, defines GABAergic neuronal fates in cerebellum. Neuron. 47:201-213.

43. Glasgow, S.M., Henke, R.M., Macdonald, R.J., Wright, C.V., and Johnson, J.E. 2005. Ptf1a determines GABAergic over glutamatergic neuronal cell fate in the spinal cord dorsal horn. Development. 132:5461-5469. 